\title{
Effect of Seed Size on Germination of Semecarpus anacardium (Marking Nut) in Garhwal Himalaya
}

\author{
P. Rathiesh*, Ajeet Kumar Negi and Dinesh Singh \\ Department of Forestry and NR, HNB Garhwal University, \\ Srinagar Garhwal, Uttarakhand, India \\ *Corresponding author
}

\section{Keyw ords \\ Seed Size, Germination, Semecarpus anacardium Garhwal Himalaya \\ Article Info \\ Accepted: \\ 24 August 2019 Available Online: 10 September 2019}

\section{A B S T R A C T}

The present study was conducted to generate information on effect of seed size on germination of Semecarpus anacardium in Garhwal Himalaya. Semecarpus anacardium is a medium sized deciduous tree, growing up to 10-15 metres in height. The plant grows naturally in tropical and subtropical climate and distributed in sub-Himalayan region, Tropical region, Bihar, Bengal, Orissa and central parts of India. It's an important medicinal plant species possessing Anti-Cancer, Anti-inflammatory and several diseases like skin disease, fungal disease, excessive menstruation, fever, constipation, etc. The experiment was carried out at HNB Garhwal University, Srinagar during 2015-2016 in CRD experimental design with five replications. There were 3 treatments namely $S_{1}$ as small seeds, $S_{2}$ as medium seeds and $S_{3}$ as larger seeds. The highest germination percent was found in $\mathrm{S}_{3}$ (Large sized seed) is $32 \%$. Thus the experiment reveals that the seed size enhances the seed germination percent of Semecarpus anacardium.

\section{Introduction}

Semecarpus anacardium Linn. an important species of the Anacardiaceae family, is commonly known as Oriental cashew nut or Marking nut in English, Dhobi nut in Hindi and Bhallataka or bhilawa in Sanskrit. It is one of the best, versatile and most commonly used trees as a household remedy, distributed in the
sub-Himalayan region, Tropical region, Bihar, Bengal, Orissa and central parts of India. It is a medium-sized deciduous tree, growing up to 10-15 metres in height. The plant grows naturally in the tropical and dry climate.

The seed contains several alkaloids, flavonoids, bioflavonoids and other components (Rao et al., 1973; Ishratulla et al., 
1977; Premalatha, 2000). Various drugs were derived from Semicarpus anacardium Linn plant which is available in the market against several diseases like skin disease, tumors, malignant growth, fungal disease, excessive menstruation, vaginal discharge, fever, haemoptysis, constipation and intestinal parasites (Jain and Sharma, 2013; Chandra, 1989). Anti-Cancer Activity, Neuroprotective Activity, Anti-inflammatory activity, Antioxidant activity, Antimicrobial activity, Anti-spermatogenic effect (Sharma et al., 2003).

Like many other medicinal species, $S$. anacardium is collected from the wild at present. As the demand for plant-based drugs is increasing, the pressure on natural resources is growing at an alarming rate (Waman and Bohra, 2016). In the absence of a sustainable replenishing strategy, rare and endemic flora is under constant threat. Existing forests have been fragmented due to anthropogenic activities which affect these species and drive them towards extinction (Prasad and Prasad, 2009). Habitat enrichment is a viable strategy to support the conservation and sustainable use of biodiversity. Seed propagation is one of the easiest yet effective methods for regenerating medicinal plants (Butola and Badola, 2004).

Generally, seed germination is controlled by many internal and external factors. Seed size is one among them. Size is an important characteristic of seed quality as larger seeds with larger volume contain more resources and are likely to exhibit greater vigour than smaller seeds (Ellis, 1992). In a range of plant species, seed size has been shown to affect germination rate, emergence rate, success of establishment, and growth (Bentley et al., 1980; Sanderson et al., 2002), which can indirectly determine plant distribution and abundance across different habitats (Silveira $e t$ al., 2012). Sowing of the mixed seed of a species may result in non-uniform density of seedlings, which may lead to heterogeneity in the vigour and size of the seedlings. The seed size often controls the germination and initial seedling growth in many tree species (Murali, 1997). Generally, bigger seeds germinate quicker and would take lesser duration when compared to that of smaller ones (Manonmani et al., 1996, Negi and Todaria, 1997; Gunaga et al., 2007). In contrast, seeds of medium to smaller produced higher seed germination in a few multipurpose trees of Jammu (Dar et al., 2002). Hence, the present study was undertaken to know the influence of seed size on germination of Semecarpus anacardium.

\section{Materials and Methods}

The present study was undertaken at HNB Garhwal University, Srinagar during 2015$2016\left(30.22^{\circ} \mathrm{N} 78.78^{\circ} \mathrm{E}\right.$ and altitude of $\left.560 \mathrm{~m}\right)$. Matured fruits were collected from trees in a natural forest near Dehradun, Lansdowne and Kalagarh Forest Division (Uttarakhand) during the end of April, 2015. Immediately after fruit collection, seeds were shade dried for about a 10 day. Healthy seeds were selected and grouped into three classes manually based on seed size such $S_{1}$ as small ( $<15 \mathrm{~mm}), \mathrm{S}_{2}$ as medium (15 to $20 \mathrm{~mm}$ ) and $\mathrm{S}_{3}$ as large (>20 mm) and Completely Randomized Design (CRD) for the experimental design, three treatments, with five replications of 50 seeds each treatments. Regular watering was done as per the requirement. Observation on daily seed germination was counted up to 45 days from the date of sowing. After germination, germinated seeds are transplanted into poly bags, Seedling growth parameters were recorded after one month of planting. Initiation of germination, germination percentage and germination capacity were calculated and plant height, collar diameter was recorded at the age of one months from date of transplanting. 
The data were subjected for analysis of variance and mean separation (least significant difference) using Web Agri Statistical Package WASP 2.0 (ICAR RC for Goa, Ela, India).

\section{Results and Discussion}

The three grades of seed viz, small $\left(\mathrm{S}_{1}\right)$, medium $\left(S_{2}\right)$ and large $\left(S_{3}\right)$ were used to see their effect on germination behaviour. It was revealed from the data in table 1 that seed size exert a significant effect on germination behaviour of Semecarpus anacardium.

The seed size usually reflects the comparative nutrient pool and energy of a seed which affects the future growth and development. The bigger seed size and more seed weight contain more amount of reserve food material in contrast to smaller seed (Athaya, 1985). These results are in line with the findings of Gurunathan et al., (2009) for Jatropha curcas. Similar results have also been reported for Emblica officinalis, Syzygium cumini, Zizyphus mauritiana and Tamarindus indica (Parameswari and Srimathi, 2009) and Pongamia pinnata (Manonmani et al., 1996).

The seed size had a significant effect on initiation of germination. The number of days taken to initiation of germination varies from 30.6 to 25.8 days. The significantly minimum initiation of germination of 25.8 days was found when large sized seed $\left(\mathrm{S}_{3}\right)$ were used. The maximum value obtained in $S_{1}$ was 30.6 days in small sized seed $\left(\mathrm{S}_{1}\right)$. This might more amount of reserve food material which helped to germinate quicker. It coincides with other research that bigger seeds germinate quicker in Emblica officinalis, Syzygium cumini, Zizyphus mauritiana and Tamarindus indica (Parameswari and Srimathi, 2009) and Jatropha curcas (Gurunathan et al., 2009).
The germination percent was significantly affected by seed size. The significantly maximum germination percent of 32.0 was found when large sized seeds $\left(\mathrm{S}_{3}\right)$ were used. However, the significantly minimum germination percent was recorded when small sized seeds $\left(\mathrm{S}_{1}\right)$ was used giving a value of 22.0 percent only. The highest germination with large and heavy seeds of various trees has been reported (Singh et al., 1973; Kandya, 1978; Santon, 1985; Kackar et al., 1986 and Manga and Sen, 1996). Similar results have been reported in Sapindus emerginatus (Venkatesh and Nagarajaiah, 2010; Suresha et al., 2007), Albizia lebbek (Mutha et al., 2004), Acacia catechu (Khera et al., 2004), Syzygium cumini (Sasthri et al., 2001), Azadirachta indica (Uniyal et al., 2007), Jatropha curcas (Singh and Saxena, 2009), Pongamia pinnata (Arjunan et al., 1994) and Leucaena leucocephala var.K8 (Sharma and Sood, 1990).

The germination capacity was significantly affected by the seed size. The significantly maximum germination capacity of 46.0 percent was recorded in large sized seeds $\left(\mathrm{S}_{3}\right)$, while the significantly minimum value of 34.0 percent was observed in small sized seeds $\left(\mathrm{S}_{1}\right)$. The present research are in line with other research in Jatropha curcas (Singh and Saxena, 2009); Eucalyptus citriodora (Aguiar and Nakane, 1983); Sapindus mukorossi (Attri, 2011).

The collar diameter was not significantly affected by the seed size. The maximum collar diameter of $4.5 \mathrm{~mm}$ was recorded in large sized seeds $\left(\mathrm{S}_{3}\right)$, while the minimum value of 3.8 was observed in small sized seeds $\left(\mathrm{S}_{1}\right)$.

The seed size had a significant effect on plant height. The significantly maximum plant height was recorded in large sized seeds $\left(S_{3}\right)$ giving a value of $13.18 \mathrm{~cm}$. 
Table.1 Effect of seed size on germination behaviour of Semecarpus anacardium.

\begin{tabular}{|l|c|c|c|c|c|}
\hline Treatments & $\begin{array}{c}\text { Initiation of } \\
\text { Germination }\end{array}$ & $\begin{array}{c}\text { Germination } \\
\text { Percentage }\end{array}$ & $\begin{array}{c}\text { Germination } \\
\text { Capacity }\end{array}$ & $\begin{array}{c}\text { Collar Diameter } \\
(\mathbf{m m})\end{array}$ & $\begin{array}{c}\text { Plant } \\
\text { Height }(\mathbf{c m})\end{array}$ \\
\hline $\mathbf{S}_{\mathbf{1}}$ & 30.6 & 22.0 & 34.00 & 3.8 & 8.2 \\
\hline $\mathbf{S}_{\mathbf{2}}$ & 27.2 & 26.0 & 38.00 & 4.34 & 10.46 \\
\hline $\mathbf{S}_{\mathbf{3}}$ & 25.8 & 32.0 & 46.00 & 4.5 & 13.18 \\
\hline Mean & 27.87 & 26.67 & 39.33 & 4.21 & 10.61 \\
\hline CD (5\%) & 1.631 & 6.657 & 9.072 & NS & 0.926 \\
\hline
\end{tabular}

*NS= Non Significant

Fig.1

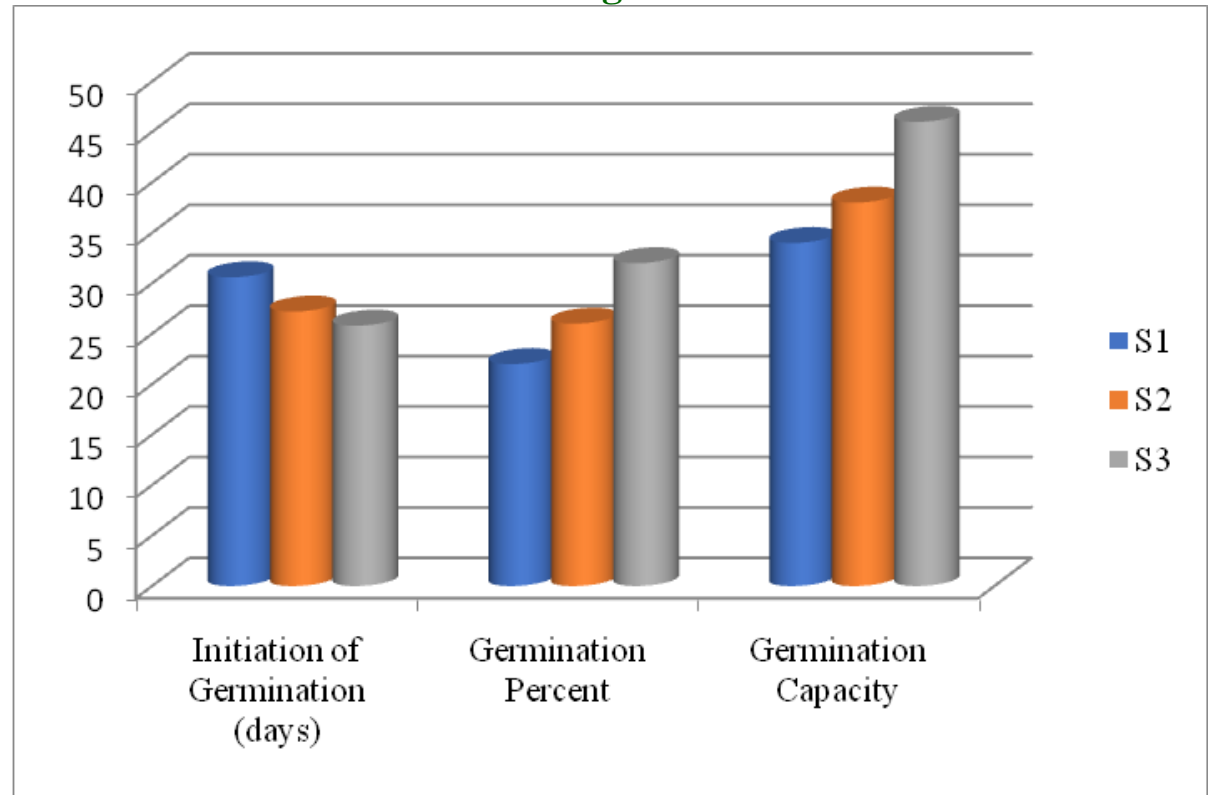

The significantly minimum value of 6.06 was obtained when small sized seeds $\left(\mathrm{S}_{1}\right)$ were used. The results are in agreement with the findings in Mammea suriga (Gunaga et al., 2008); Pongamia pinnata (Arjunan et al., 1994); Similarly, Khera et al., (2004) reported in Acacia catechu, Acacia nilotica and Dalbergia sissoo showed a positive relationship with the germination and related parameters with growth of seedling.

The present results showed that seed grading is an essential step to improve the germination and produce vigorous seedlings. Use of large sized seeds could help improve quality of nursery stock as well as their performance at field condition. A Large number of seedlings produced following seed size could be ideal for afforestation programmes for the conservation of this species, for broadening the resource base to obtain the raw material for traditional medicines, and possible exploitation as rootstocks to related species.

\section{Acknowledgments}

The authors are grateful to the HNB Garhwal University and Forest College and Research Institute, Tamil Nadu Agricultural University for providing the necessary facilities and constant encouragement. 


\section{References}

Aguiar, I.B. de, and Nakane, J.T. (1983). Seed size of Eucalyptus citriodora: influence on germination and vigour. Brasil Florestal,13(53): 25-28.

Arjunan M C, Antony K A, Ponnammal N R. 1994. Effect of seed size on germination viability and seedling biomass in Pongamia pinnata Pierre. VanVigyan 32 (1/2): 23-28

Athaya C D. 1985. Ecological studied of some forest tree seed I. seed morphology. Indian Journal of Forestry 8 (1): 33-36.

Attri, V. 2011. Effect of seed size and organic manures on germination parameters and seedling biomass of Sapindus mukorossi Garten. M. Sc. Thesis, Dr. YSP UHF, Nauni, Solan (H.P), India. 73 p.

Bentley, S., Whittacker, J. B and Malloch, A. J. C. 1980. Field experiments on the effects of grazing by a chrysomelid beetle (Gastrophysa viridula) on seed production and quality in Rumex obtusifolius and Rumex crispus. Journal of Ecology, 68: 671-674.

Butola JS, Badola HK (2004) Effect of presowing treatment on seed germination and seedling vigour in Angelica glauca, a threatened medicinal herb. Current Science 87:796-799

Chandra, Y. R., 1989. The wealth of India row material. CSIR; New Delhi.

Dar, F.A., Gera, M. and Gera, N., 2002, Effect of seed grading on germination pattern of some multi purpose tree species of Jammu region. Indian Forester 128: 509-512.

Ellis, R. H. 1992. Seed and seedling vigor in relation to crop growth and yield. Plant Growth Regulation, 11: 249-255.

Gurunathan N, Srimathi P and Paramathma M. 2009. Influence of size polymorphism on seed and seedling quality of Jatropha curcas. Madras Agricultural Journal 96 (1/6): 62-66

Ishratulla K, Ansari WH, Rahman W, Okigawa M, Kawano N (1977) Biflavonoids from Semecarpus anacardium Linn.
(Anacardiaceae). Indian Journal of Chemistry 15B:617-619.

Jain Paras and Sharma H.P, 2013. A potential Ethnomedicinal plant: Semecarpus anacardium Linn. - A Review, International Journal of Research in Pharmacy and Chemistry, 3(3): 564 -572.

KacKar N L, Solanki K R and Jindal S K. 1986. Variation in seed and fruit characters of Prosopis cineraria (L) MacBride in the Thar desert. Indian Journal of Forestry 9: 113-115.

Kandya A K. 1978. Relationship among seed weight and various growth factors in Pinus oocarp Schide. seedlings. Indian Forester 104 (8): 561-567.

Khera N, Saxena A K and Singh R P. 2004. Seed size variability and its influence on germination and seedling growth of five multipurpose tree species. Seed Science and Technology 32 (2): 319-330.

Manga V K and Sen D N. 1996. Genetic parameters of seed traits in Prosopis cineraria (L) MacBride. Indian Journal of Forestry 19: 148-151.

Manonmani V, Vanangamudi K and Rai R S V. 1996. Effect of seed size on seed germination and vigour in Pongamia pinnata. Journal of Tropical Forest Science 9 (1): 1-5.

Murali K S. 1997. Patterns of seed size, germination and seed viability of tropical tree species in Southern India. Biotropica 29 (3): 271-279

Mutha Neeta, Bohra M D, Burman Uday and Harsh L N. 2004. Effect of seed size and pretreatments on germination of Albizia lebbek (L.) Benth. Indian Journal of Forestry 27 (1): 11-14.

Parameswari k and Srimathi P. 2009.Seed size influencing seed quality in few tree crops. International Journal of Plant Sciences 4 (1):208-211.

Prasad B, Prasad R, 2009. Selection of suitable growth regulators and its concentration for better germination and seedling growth of Himalayan Dogwood (Benthmidia capitata Wall ex. Roxb.). Indian J For 32(4):523-527. 
Premalatha B, 2000. Semecarpus anacardium Linn nut - a boom in alternative medicine. Indian Journal of Experimental Biology 38:1177-1182.

Rao NSP, Row LR, Brown RT (1973) Phenolic constituents of Semecarpus anacardium. Phytochemistry 12(3):671-681

Sanderson, M. A., Skinner, R., H., and Elwinger, G. F. 2002. Seedling Development and Field Performance of Prairiegrass, Grazing Bromegrass, and Orchardgrass. Crop Science, 42: 224-230.

Santon M L.1985. Seed size and emergence time with in a stand of Wild radish (Rhapanus sativus L.): establishment of fitness hierarchy. Oecologia 67:524- 531.

Sasthri G, Srimathi P and Malarkodi K. 2001. Effect of seed size on seed quality in jamun. Madras Agricultural Journal 88 (7/9): 524-526

Sharma A, Verma P.K and Dixit V.P. 2003. Effect of Semecarpus anacardium fruits on reproductive function of male albino rats. Asian J Androl. 5:121-124.

Sharma K K and Sood O P. 1990. Germination behaviour of seeds of Leucaena leucocephala as influenced by various treatments and seed sizes. Van Vigyan 28 (3): $99-105$

Silveira, F. A. O., Negreiros, D., Araújo, L. M. and Fernandes, G. W. 2012. Does Seed Germination Contribute to Ecological Breadth and Geographic Range? A Test with Sympatric Diplusodon (Lythraceae) Species from Rupestrian Fields. Plant Species Biology, 27: 170-173.

Singh Nidhi and Saxena A K. 2009. Seed size variation and its effect ongermination and seedling growth of Jatropha Curcas L. Indian Forester 135(8): 1135-1142

Singh R V, Chandra J P and Sharma S N. 1973. Effect of depth of sowing on germination of kail seeds. Indian Forester 99 (6):367371.

Suresha N L, Balachandra H C and Shivanna H. 2007. Effect of seed size on germination, viability and seedling biomass in Sapindus emerginatus (Linn). Karnataka Journal of Agricultural Sciences 20 (2): 326-327.

Uniyal A K, Singh Bhupendra and Todaria N P. 2007. Effect of seed size, sowing orientation and depth on germination and seedling growth in neem, Azadirachta indica. Seed Technology 29 (1): 68-75.

Venkatesh L and Nagarajaiah C. 2010. Effect of seed size on germination, viability and seedling biomass in Sapindus emerginatus Linn. Environment and Ecology 28 (1): 25-27.

Waman AA, Bohra P (2016) Sustainable development of medicinal and aromatic plants sector in India: an overview. Sci Cult 82:245-250.

\section{How to cite this article:}

Rathiesh, P., Ajeet Kumar Negi and Dinesh Singh 2019. Effect of Seed Size on Germination of Semecarpus anacardium (Marking Nut) in Garhwal Himalaya. Int.J.Curr.Microbiol.App.Sci. 8(09): 2590-2596. doi: https://doi.org/10.20546/ijcmas.2019.809.300 